\title{
A LOUCURA NA LITERATURA FANTÁSTICA DO SÉCULO XIX: O RESGATE DA VOZ DO LOUCO COMO QUESTIONAMENTO DA NORMA
}

\author{
THE MADNESS IN THE NINETEENTH CENTURY'S FANTASTIC LITERATURE: THE \\ REDEEM OF THE MADMAN'S VOICE AS A QUESTIONING OF THE NORM
}

Elaine Cristina dos Santos Silva

Universidade Estadual Paulista "Júlio de Mesquita Filho"

RESUMO: Diferentemente dos discursos comuns, a fala do louco é ambígua, revela a impossibilidade do conhecimento seguro sobre o mundo. $O$ louco percebe as inconsistências da realidade e dá lugar a esse discurso, discordando do "discurso correto", evidenciando o caráter fragmentário e problemático do mundo e a experiência de habitá-lo. Refletindo sobre alguns contos do autor francês Guy de Maupassant (18501893), demonstraremos a maneira como o autor, cuja obra reúne abundante número dessas personagens, retrata o louco e, assim, poderemos refletir acerca da desorganização da personalidade. Sabendo que a loucura é um conceito historicamente forjado, que muda conforme mudam as sociedades, investigaremos como se dá a construção formal da loucura no século XIX, que encontra suporte adequado na literatura fantástica praticada por autores como Maupassant. De acordo com Bessière (1974), esse tema remonta ao questionamento da cultura, na qual o indivíduo não se encaixa ou consegue expressar plenamente sua individualidade. Daí a importância do resgate da voz do louco pela literatura, pois, se o discurso científico isola a loucura e a desqualifica em favor da razão, o discurso literário resgata esteticamente essa voz para propor questionamentos e relativizar a lógica das práticas cotidianas por meio dos mecanismos formais da arte.

PALAVRAS-CHAVE: Loucura; Literatura fantástica; Guy de Maupassant.

ABSTRACT: Unlike common speech, the madman's speech is ambiguous and reveals the impossibility of certain knowledge about the world. The madman realizes the inconsistencies of reality and gives space to that speech, disagreeing with the "correct speech", showing the fragmentary and problematic character of the world and the experience of inhabiting it. Reflecting on some tales of French author Guy de Maupassant (1850-1893), we will demonstrate how the author, whose work brings abundant number of these characters, portrays the madman and, thus, we can reflect on the personality disorders. Knowing that madness is a historically forged concept, which changes as societies change, we will investigate how is made the formal construction of madness in the nineteenth century, which finds adequate support in the fantastic literature practiced by writers like Maupassant. According to Bessière (1974), this issue goes back to the question of culture, in which the individual do not fit or cannot fully express his individuality. Hence the importance of the redeem of the madman's voice by literature, because if the scientific discourse isolates madness and disqualifies it in favor of reason, the literary discourse aesthetically rescues that voice to propose questions and relativize the logic of everyday practices through the formal mechanisms of art.

KEYWORDS: Madness; Fantastic literature; Guy de Maupassant. 


\section{Revista do SELL}

v. 5 , no. 2

ISSN: $1983-3873$

A loucura, conforme compreendemos, é um fenômeno socialmente percebido; sendo assim, cada sociedade, em cada contexto, tem uma percepção e, por consequência, um posicionamento a seu respeito. Nosso entendimento sobre esse assunto vai ao encontro do que defende Michel Foucault, em seu História da loucura na idade clássica (1972), obra na qual o autor demonstra que o conceito de loucura muda conforme mudam as sociedades que o legitimam. Isso nos leva à conclusão de que a loucura é situada no tempo e no espaço, historicamente forjada, não tão natural quanto parece.

Por concebermos a loucura dessa maneira, o século XIX, contexto de produção do nosso corpus (que apresentaremos adiante) coloca-se em nosso horizonte. Essa época é bastante significativa para nós, pois, nesse momento, o homem passava por uma crise intelectual que abriu as portas para muitas artes explorarem o campo da dúvida e da hesitação. Na literatura, esse cenário torna-se perfeito para o surgimento de uma narrativa de caráter questionador, que coloca em xeque forças conflitantes: a narrativa fantástica ${ }^{1}$.

Conforme se sabe, e lembra Carvalho (2011), o pensamento teocêntrico da época medieval acolhia bem a ideia da relação entre um plano real - entendido como a nossa realidade cotidiana - em harmonia com um plano suprarreal; nessa relação os dois planos não apenas coexistiam, mas até se explicavam. A certeza da convivência entre esses dois mundos era tão viva na época medieval que levou, por exemplo, muitas mulheres à fogueira por "comprovada" bruxaria. Com o lluminismo, a interferência do sobrenatural na vida cotidiana começa a ser questionada e isso desmantela o equilíbrio anterior, pois os filósofos e cientistas utilizavam o grande prestígio do qual passaram a gozar para encorajar a rejeição de tudo o que não pudesse ser explicado ou provado à luz da razão.

Atingindo especialmente Inglaterra, Alemanha e França, esse movimento, que tinha como pressuposto a valorização da razão humana, estava ancorado no grande progresso técnico e científico até então alcançado. A segurança trazida pelo conhecimento,

\footnotetext{
${ }^{1}$ De acordo com Introduction à la littérature fantastique (1970), de Tzvetan Todorov, o fantástico seria uma categoria evanescente, situada entre duas outras, a do estranho e a do maravilhoso. Uma das noções mais importantes na teoria desse autor está na questão da hesitação do leitor. Diante de um fato que desafie as leis naturais, o leitor teria, para Todorov, duas possibilidades: acreditar no que é relatado como referente à ordem do sobrenatural, ou à ordem do natural; se o leitor for levado à primeira opção, estará diante do que Todorov designa "maravilhoso", se caminhar para a segunda, diante do "estranho". O fantástico estaria na impossibilidade de solução, na hesitação do leitor, que não pode decidir se o texto é maravilhoso ou estranho.
} 


\section{Revista do SELL}

v. 5 , no. 2

ISSN: $1983-3873$

entretanto, não era absoluta. O homem ainda não era capaz de encontrar todas as respostas para suas perguntas na ciência e, como agravante, também perdera a antiga estabilidade proporcionada pelo sobrenatural e pelas explicações dadas pela Igreja.

Se, por um lado, o homem do século XVIII recebia as ainda fortes influências da Igreja Católica, por outro, o lluminismo reclamava sua atenção. O contato com novas ideias que se chocavam diretamente com as antigas gera a confusão, a dúvida, a hesitação e o enfrentamento entre credulidade e ceticismo, marcas da estética fantástica. Nesse ambiente, no qual o homem passa a se ver e a se definir não mais por sua função social, mas a partir do seu caráter individual, enquanto ser único, dotado de pensamentos e desejos, diferente de como era na época medieval, destacamos a rejeição do caráter imutável dos valores morais, estéticos ou políticos, pois todas as "verdades incontestáveis" passavam a ser questionadas.

Nesse cenário, os românticos, conforme Roas (2001), embora não negassem as conquistas da ciência, mostravam que a razão tinha limitações; por isso, não deveria ser o único instrumento para captar a realidade. Para os românticos, a intuição e a imaginação eram meios tão válidos quanto a razão para entender e explicar o mundo. Isso, para Roas, explicaria a reação do Romantismo às ideias mecanicistas, surgidas com o Iluminismo, que consideravam o universo como uma máquina. Essa compreensão do universo soava, aos românticos, limitadora, por não corresponder a como viviam; o universo não se aproximava de uma máquina previsível e não podia ser pensado nem refletido assim pela arte. $O$ universo deveria ser algo muito mais misterioso, "como devia ser também a alma humana"2 (ROAS, 2001, p. 23).

$O$ interesse pelas questões mais íntimas e profundas do ser humano leva o fantástico, com muita frequência, a enveredar pelos mistérios da mente humana, razão pela qual interessa-nos as observações de Luis Vax (1974) sobre o aspecto mental ligado ao fantástico; o autor lembra-nos da estreita relação que as narrativas fantásticas mantinham com as disciplinas da medicina que cuidavam dos transtornos mentais. Os fantasmas, por exemplo, não têm uma comprovável existência no mundo real, mas eles gozam de uma existência subjetiva nas mentes vitimadas por alucinações. Da mesma maneira, os pressentimentos ou sentimentos estranhos, tão comuns aos heróis fantásticos, podem ser associados a quadros de esquizofrenia ou paranoia.

2 "como debía de serlo también el alma humana". Traduções de nossa autoria. 


\section{Revista do SELL \\ v. 5 , no. 2 \\ ISSN: $1983-3873$}

Essa aproximação entre o fantástico e aspectos da medicina psiquiátrica não só inspirou muitos autores nos séculos XVIII e XIX (dentre eles, Guy de Maupassant) como confere ao fantástico, conforme Vax (1974), um grau de seriedade que o afasta da fantasia gratuita. Prova disso são as admiráveis descrições, oriundas da literatura fantástica, a respeito de perturbações mentais, as quais surpreendiam os alienistas. Isto não significa, em absoluto, admitir a possibilidade de se confundir o discurso literário com os estudos psiquiátricos. Parafraseando Vax (1974), enquanto os médicos registram as alucinações procurando encontrar origens físicas ou psíquicas a fim de tratar seus pacientes, a literatura pretende-se artística e não cede ao caráter puramente utilitário da escrita científica; embora o discurso médico tenha servido, diversas vezes, para embasar críticas literárias ou inspirar escritores, o discurso literário não se rende a ele. Muito além de construir uma narrativa coerente com os preceitos da medicina, a preocupação do artista (nesse caso, o escritor) concentra-se em criar algo esteticamente interessante, belo. Soma-se a isso o fato de que a "cura", desejada pela psiquiatria do século XIX, pressupõe que a loucura seja um problema que deve ser eliminado por meio do ajuste do indivíduo afetado à ordem corrente. Foucault, em O poder psiquiátrico (2006), explicita que o processo de cura do indivíduo louco envolve a sujeição do indivíduo à lei do outro, realizada nos asilos, e nesse sentido os asilos não diferem tanto dos quartéis, das escolas, dos orfanatos ou das prisões. Já a literatura não se compromete ou mesmo se preocupa com a cura do louco, pois seu discurso desconcertante não a incomoda, pelo contrário, a nutre com as visões alternativas da realidade que o discurso científico procurava abafar em favor da manutenção da ordem.

Lembrando aqui as palavras de Bessière, o fantástico tem uma propriedade ideológica, não tanto por suas imagens, comumente bastante explícitas, mas pelos elementos de organização narrativa. A autora considera o fantástico como uma escritura libertadora, fundamentada numa visão crítica e contestadora da realidade: "o disparate, o equívoco, a incoerência, escolhidas, não rejeitam simplesmente o concreto e não dão somente a conhecer o imaginário"3 (BESSIÈRE, 1974. p. 213). Nesse sentido, a loucura, mais que um tema curioso, serve como reflexão sobre a inadequação do sujeito frente ao caráter imperativo da norma, à qual não se ajusta.

Segundo a autora, o fantástico seria a narrativa dos limites: o limite entre o ser e o não ser, entre o ser e o parecer e da afirmação ou da negação do sujeito. Utilizando o

\footnotetext{
3 "la disparate, l'équivoque, l'incohérence, choisies, ne rejettent pas simplement le concret et ne donnent pas seulement à connaître de l'imaginaire".
} 


\section{Revista do SELL \\ v. 5 , no. 2 \\ ISSN: $1983-3873$}

improvável, o fantástico consegue relativizar até mesmo a noção de limite: contrariando as regras do natural e do sobrenatural, por exemplo, o indivíduo é sempre colocado além das convenções admitidas. O fantástico propõe, por meio da infração das normas, outra regulação do mundo, que não passe pela cultura ou crenças vigentes. Dessa maneira, o fantástico representaria a autonomia absoluta do sujeito.

Guy de Maupassant (1850-1893) escreveu seus contos e novelas durante o século XIX, momentos de eclosão do fantástico, por isso não deve nos surpreender que tenha tomado gosto por esse tipo de narrativa, aproveitando o espaço conferido por esta para o questionamento dos limites e as reflexões sobre as patologias presentes no corpo e no espírito humano.

Ao mudar-se para Paris, com o apoio de Gustave Flaubert, amigo de sua família, Maupassant ingressou no meio literário, publicando seus textos em jornais. Seu círculo literário expandiu-se e conheceu outros escritores de seu tempo, como Émile Zola (18401902) e Ivan Turgueniev (1818-1883), os quais também influenciaram sua obra. A fragilidade de sua saúde, entretanto, o impediu de ter uma carreira literária muito longa; apesar disso, escreveu mais de trezentos contos, novelas, crônicas e seis romances. A descoberta da sífilis levou Maupassant a passar por duros momentos de depressão e recorrer a narcóticos, o que agravou sua saúde já muito delicada. Com apenas 43 anos de idade, Maupassant morreu em 1893, deixando uma literatura marcada pelo pessimismo, muitas vezes associada aos complicados últimos anos de sua vida, à guerra franco-prussiana (da qual participou) e aos conflitos familiares vivenciados na infância.

A visão profundamente pessimista do mundo, de uma sociedade injusta, do homem como uma criatura mal feita condenada à solidão e de Deus (se se pudesse admitir sua existência) como o pior dos criminosos, deve ser compreendida como um estilo conscientemente executado, uma vez que a arte não poderia deixar de refletir o pessimismo e o desencantamento sentidos naquela época. Como muitos intelectuais de seu tempo, Maupassant recebeu influências de Arthur Schopenhauer (1788-1860), como podemos perceber, por exemplo, em "Lettre d'un fou", um dos contos do qual nos ocuparemos neste artigo. Embora não com o rigor do discurso filosófico, mas por meio do trabalho literário, Maupassant trata da limitação da inteligência do homem, cujos sentidos grosseiros só poderiam transmitir uma visão parcial, imperfeita, do mundo, tema a respeito do qual Schopenhauer também refletia. 


\section{Revista do SELL}

v. 5 , no. 2

ISSN: $1983-3873$

Antes de nos demorarmos mais sobre a análise da obra de Maupassant, cabe uma breve apresentação do corpus que utilizamos para o estudo apresentado neste artigo. Para este trabalho, selecionamos vinte e três narrativas, entre os contos e novelas do escritor francês, pois encontramos em todas elas claras referências à loucura e a personagens que, em alguma medida, sucumbiram aos males da mente, tornando-se úteis para nossa reflexão. A respeito dos textos selecionados, são eles: "Fou ?" (1882); "La folle" (1882); "Madame Baptiste" (1882); "Un parricide" (1882); "Denis" (1883); "La main d'écorché" (1883); "La reine Hortense" (1883); "L'enfant" (1883); "Lui ?' (1883); "Mademoiselle Cocotte" (1883); "La chevelure" (1884); "Un fou ?' (1884); "La petite Roque" (1885); "Lettre d'un fou" (1885); "Un fou" (1885); "L'auberge" (1886); "Un cas de divorce" (1886); "Le Horla" (primeira versão, 1886); "Le Horla" (segunda versão, 1887); "L'homme de Mars" (1887); "Madame Hermet" (1887); "Qui sait?' (1890) e "Le docteur Héraclius Gloss" (1921).

Passando muito rapidamente por cada narrativa, temos em "Fou ?" um homem que, recordando a própria história, pergunta a si mesmo e ao leitor se ele é um louco, pois, durante uma crise de ciúmes, mata sua esposa e o cavalo dela.

Em "La folle", uma jovem perde o pai, o marido e o filho, e sua tristeza a faz mergulhar em um estado catatônico que dura anos. A história se passa durante a guerra franco-prussiana e é contada por um vizinho dessa jovem, que vê a casa dela ser tomada por soldados, os quais imaginam que o estado da jovem é na verdade um ato de rebeldia e a abandonam numa floresta, onde é devorada por lobos.

No conto "Madame Baptiste", o narrador vê um cortejo fúnebre e é informado de que aquela morta fora violentada quando muito jovem e sofreu com os estigmas que a sociedade the impôs até se casar com um bom homem e começar a retomar sua vida. Entretanto, em uma cerimônia, quando a chamaram pelo nome de Baptiste, nome que fazia referência ao ato violento do qual fora vítima, ela enlouqueceu e terminou por se atirar em um rio.

Em "Un parricide", um acesso de loucura é a única explicação que o tribunal encontra para um crime cometido contra um casal muito querido na cidade. O homem que confessou o crime imaginava que aqueles eram seus pais que o abandonaram na infância e que fariam isso novamente; então, durante uma confusão, matou o casal e jogou os corpos no rio Sena. 


\section{Revista do SELL}

v. 5 , no. 2

ISSN: $1983-3873$

Um acesso de loucura também é a explicação utilizada em "Denis" para a tentativa de assassinato que o protagonista pratica contra seu chefe, homem pacato e com quem mantinha boa relação.

No conto "La main d'écorché", durante uma soirée, Pierre aparece trazendo a mão de um defunto. Alguns dias depois, o amigo de Pierre corre para sua casa, pois soubera que este tinha sofrido uma tentativa de estrangulamento. Pierre sobreviveu, mas perdeu a razão, e seu amigo notou que a mão do defunto havia desaparecido. Em seu último delírio, Pierre grita desesperadamente que tentavam sufocar-Ihe e morre em seguida. Durante seu enterro o coveiro encontrou outro caixão na cova que abriram para Pierre, e dentro dele um homem morto sem uma das mãos, a qual se encontrava ao lado.

"La reine Hortense" narra a história de uma senhora (ela não era da realeza, mas era chamada de rainha por seu porte) que vivia sozinha, longe da família e sem amigos. Doente, Hortense começou a delirar e em seus delírios falava de seu marido e filhos (os quais nunca tivera). Sua última frase antes de morrer foi um grito de preocupação sobre quem cuidaria de suas crianças.

Maupassant tem dois contos com o título "L'enfant", um publicado em 1882 e um no ano seguinte. Interessa-nos esse segundo, no qual, durante um jantar, um médico defende o direito das mulheres ao aborto baseado em uma história que acompanhara de perto. Uma de suas pacientes, viúva pela terceira vez, estava à beira da loucura por suas perdas e acabou grávida de seu jardineiro. Sentindo-se culpada e temendo um escândalo que afetasse sua família, aquele filho em seu ventre a enlouquecia. Um dia abriu o próprio ventre com uma faca para atirar a criança na lareira, mas perdeu os sentidos e morreu esgotada antes que concluísse sua ação.

Em 'Lui ?', um amigo escreve a outro para dizer que vai se casar, entretanto, não o faz por amor, mas porque tem medo de ficar sozinho, pois toda vez que isso acontece ele sente a presença de outra pessoa, uma espécie de duplo que o acompanha.

"Mademoiselle Cocotte" é segunda versão de uma mesma história, primeiramente publicada sob o título "Histoire d'un chien", em 1881. Nessa segunda versão, Maupassant altera o final da história, incluindo a temática da loucura. Nesse conto, um cocheiro é obrigado a matar sua cachorrinha de estimação e, não vendo outra saída, joga o animal no rio Sena com uma pedra amarrada ao pescoço. Meses depois, nadando nesse mesmo rio, o cocheiro encontra uma carcaça e, examinando mais de perto, reconhece sua cachorra. Aterrorizado, ele foge completamente nu e louco. 


\section{Revista do SELL}

v. 5 , no. 2

ISSN: $1983-3873$

Em "La chevelure" o narrador tem acesso ao diário de um dos loucos (da época que ainda não estava completamente entregue a seu delírio) do sanatório que vai visitar, onde lê a historia daquele homem, obcecado por uma mecha de cabelo de mulher que encontrou em um móvel antigo a ponto de sentir a presença de sua dona.

"Un fou ?' traz a história de um louco que havia morrido num sanatório, contada por um conhecido seu, que relata a estranheza desse homem que nunca mostrava as mãos, pois acreditava ter um poder cujas referências ao magnetismo são claras.

Um carteiro, em "La petite Roque", encontra o corpo de uma jovem nua próximo a um rio e avisa as autoridades, que concluem que a jovem foi violentada antes de sua morte, mas nenhum dos suspeitos é preso por falta de provas. O prefeito, culpado do crime, acreditando ser assombrado pela morta, atira-se do alto da torre de seu castelo.

Em "Lettre d'un fou" um homem escreve para seu médico para perguntar se está louco, descrevendo seus sentimentos e em particular a impressão que tem de que os sentidos humanos são muito pouco para compreender a realidade em sua totalidade $e$ isso o faz temer tudo a sua volta. Num de seus esforços para melhor apreender o mundo, ele confessa ter visto um ser invisível.

O diário de um irrepreensível magistrado que morrera é encontrado em "Un fou". O autor do diário escreve sobre ter matado um jovem apenas para saciar seu crescente desejo de matar e confessa ter se valido da sua posição de juiz para condenar outra pessoa pelo crime que ele cometera. Os médicos que tiveram acesso ao diário consideraram seu dono louco.

Em "L'auberge", dois homens são contratados para guardar uma propriedade durante o inverno; mas um deles, perdendo o juízo por causa do isolamento imposto pelas montanhas geladas, mata seu companheiro e termina alcoólatra e ouvindo vozes.

No conto "Un cas de divorce", na tentativa de conseguir o divórcio de sua cliente, o advogado lê o diário de seu marido para provar ao juiz que aquele homem está louco, pois negligencia sua esposa por amor às flores.

"Le Horla" foi escrito em duas versões, a primeira publicada em 1886 e a outra em 1887; ambas nos interessam nesse estudo, pois trabalham com a questão da loucura. Nas duas versões, com pequenas alterações de enredo, entramos em contato com as alucinações de um homem que acredita ver um ser invisível e mau que o persegue e o leva à loucura.

Em o "L'homme de Mars" o narrador recebe a visita de um estranho homem que, enquanto tenta convencê-lo de que Marte é habitado, faz críticas a toda humanidade. 


\section{Revista do SELL}

v. 5 , no. 2

ISSN: $1983-3873$

O narrador de "Madame Hermet" é convidado por um médico, durante visita a um sanatório, a conhecer o caso que este achava mais interessante, de uma mulher que imaginava ter o rosto coberto de marcas (o que não era verdade), pois se sentia culpada por não ter cuidado de seu filho doente por medo de ser contaminada.

Já em "Qui sait?" o narrador decide se internar em uma casa de loucos, não por se considerar nessa condição, mas porque tem medo das visões que tivera de sua mobília abandonando sua casa.

Finalmente, em "Le docteur Héraclius Gloss", a busca pela verdade filosófica faz o protagonista enveredar pelos caminhos da metempsicose e a radicalização de suas ideias sobre o assunto acaba por levá-lo ao sanatório.

Conforme afirmamos, e sendo possível perceber pelos breves resumos de cada narrativa que constitui nosso corpus, em todos esses textos há claras referências à loucura; entretanto, percebemos que na obra de Maupassant, apesar de esta temática ser recorrente, não se manifesta da mesma maneira nem com a mesma intensidade em cada uma de suas narrativas.

Louis Forestier, em nota à edição de Contes et nouvelles (1974), de Maupassant, afirma que os lugares de encontro entre o sobrenatural e a demência (lugares muito caros à literatura fantástica, acrescentaríamos) são notados na obra do autor francês desde muito cedo, mas acentuam-se especialmente em "Lui ?', "Un fou ?', "Fou ?' e "Le Horla" (em suas duas versões). Acrescentaríamos ainda outras narrativas nessa mesma categoria, das que trabalham no espaço entre o sobrenatural e demência, como "La main d'écorché", "La chevelure", "La petite Roque", "Lettre d'un fou", "L'auberge" e "Qui sait".

Em outro grupo podemos colocar: "La folle", "Madame Baptiste", "La reine Hortense", "L'enfant", "Mademoiselle Cocotte" e "Madame Hermet", pois a loucura das personagens dessas narrativas é desencadeada da mesma forma, por grandes golpes emocionais com os quais suas mentes não puderam lidar.

Podemos perceber ainda um terceiro grupo de loucos, aqueles que parecem razoáveis, mas que são tratados como insanos para que se obtenha algum benefício (ser tratado como louco em certos contextos, como nos julgamentos de crimes, por exemplo, pode ser uma vantagem), ou para que alguma atitude incomum possa ser explicada. Nessa categoria colocamos: "Un parricide", "Denis", "Un fou", "Un cas de divorce" e "L'homme de Mars".

Há ainda o caso de "Le docteur Héraclius Gloss". Esta novela, publicada postumamente, em 1921, segundo biógrafos, foi escrita aproximadamente em 1875 e 


\section{Revista do SELL \\ v. 5 , no. 2 \\ ISSN: $1983-3873$}

seria uma das primeiras novelas do autor francês. Chama a atenção o fato de que, mesmo antes de escrever suas obras mais célebres, Maupassant já demonstrava o gosto pelo tema da loucura. Nessa novela fica evidente a dicotomia entre crença e descrença no pensamento científico e também no metafísico, pois ambos não se mostram plenamente capazes de satisfazer o homem desnorteado, temática que se liga inteiramente aos debates propostos pela literatura fantástica da época.

Conforme Foucault, a loucura é percebida por meio de uma relação negativa com a razão. Dessa maneira, o louco seria aquele que não possui a razão. Ainda segundo o autor, a questão da sanidade é difícil de determinar; no entanto, "quanto menos precisa é, mais facilmente é reconhecida. Na própria medida em que não sabemos onde começa a loucura, sabemos, através de um saber quase incontestável, o que é o louco" (FOUCAULT, 1972, p. 200). Boissier de Sauvages (apud FOUCAULT, 1972, p. 200-201) procura explicar a distinção tão certa que fazemos do louco, embora tão confusa quando pensamos nos critérios utilizados. De acordo com o autor, sabemos que um homem age com a razão sadia quando observamos em seus gestos, movimentos, desejos, discursos e raciocínios uma ligação entre si e o fim para o qual se direcionam. Da mesma maneira, sabemos que alguém é vítima de uma alucinação ou de um delírio quando é possível perceber a discordância entre as ações do indivíduo e a conduta comum a outros homens. Pensando dessa forma, consideramos alguém como louco só em relação a outro, julgado não louco; isso deixa o critério bastante subjetivo, além de, como salienta Foucault, indireto, pois é possível reconhecer a loucura somente com referência à razão. Embora saibamos muito bem distinguir um indivíduo louco de um são, não sabemos distinguir tão bem qual é fronteira que separa a razão da loucura.

A loucura é sempre definida por algum traço distintivo por meio do qual podemos determinar o louco como diferente do padrão da sociedade na qual vive, como aquele cuja lógica desafia a ordem comum das coisas. Dessa maneira, conforme já salientamos, o próprio louco não se define como louco, são os outros indivíduos, os quais reconhecem nele características de pensamento e de conduta não próprias aos demais membros da sociedade.

A esse respeito chamamos a atenção para as personagens loucas nos contos e novelas de Maupassant, que circulam entre tantas outras consideradas normais, em 


\section{Revista do SELL}

v. 5 , no. 2

ISSN: $1983-3873$

relação às quais podemos perceber sua loucura. É o tratamento dispensado pelo narrador, por exemplo, o que permite o leitor tratar a sofrida jovem de "La folle" como louca - "Eu tinha então por vizinha uma espécie de louca [...]"4 (MAUPASSANT, 1974, p. 669) -, assim como é o descrédito de um discurso que antes poderia ter passado por razoável (pois demonstra progressão coerente de raciocínio) o que autoriza o leitor de "Le docteur Héraclius Gloss" a apoiar o internamento do protagonista em um sanatório. Mesmo quando as personagens assumem a própria loucura, como, por exemplo, em "Lui ?" e "Qui sait ?", contos nos quais os protagonistas tratam suas visões como alucinações, não como experiências de fato vividas, elas consideram-se loucas a partir dos momentos de lucidez, nos quais são capazes de comparar situações normais às vividas por elas.

As desordens do pensamento também podem ser percebidas por sinais exteriores, como no caso do homem que corre nu depois de perder o juízo, em "Mademoiselle Cocotte", ou de Jacques Parent, que jamais mostra as mãos, em "Un fou?' (situações que já sugerem a negação dos padrões de comportamento por parte do louco). Mas é especialmente no corpo dos loucos que os sinais do estado degenerado de suas mentes se manifestam, como se corpo e mente definhassem ao mesmo tempo. Assim, não raro encontramos descrições de corpos magros, cabelos brancos, desgrenhados ou olhares estranhos e perturbados como marcas da loucura na literatura, o que ocorre também na obra de Maupassant. Esse é o caso, por exemplo, de Ulrich, em "L'Auberge", quando a família Hauser volta a sua propriedade e com dificuldade reconhece o homem que havia contrado para cuidar do local, tamanha a mudança em sua aparência depois da loucura.

A visão da loucura e, consequentemente, do louco, mudou muito no decorrer do tempo, mas sua condição marginalizada é uma constante. A exclusão do louco por parte dos demais membros da sociedade, que não o enxergam como igual, também é uma constante apresentada em nosso corpus e contribui para 0 desenrolar trágico das situações. A solidão das personagens principais, que não têm amigos, família ou amores (tenham as personagens se afastado do mundo por vontade própria ou tenha sido essa condição imposta pelas circunstâncias), propicia a ocasião para que os terrores, angústias e mesmo desejos se manifestem e tomem conta de suas mentes fragilizadas. Nesse ponto cabe a perspicaz observação de Caroline Quesnel (1991) a respeito dos loucos na obra de Maupassant, pois, mesmo que em alguns casos a loucura transpareça em seus corpos, é pela monomania, pela obsessão, pela ideia fixa que podemos destacá-los. Esse

\footnotetext{
4 “J'avais alors pour voisine une espèce de folle [...]".
} 


\title{
Revista do SELL
}

v. 5 , no. 2

ISSN: $1983-3873$

tipo de loucura é extremamente interessante, especialmente se pensarmos no contexto de silenciamento da loucura sentido no século XIX:

\begin{abstract}
"A obsessão da ideia fixa" não é visível nem sobre o corpo nem nos gestos cotidianos do louco, é necessário, antes, procurar os sinais entre as palavras balbuciantes e desajeitadas que pronuncia. Assim, antes de declarar um personagem louco, os representantes da razão não têm outra escolha a não ser se colocar a escutar o alienado, a escutar o discurso da loucura. ${ }^{5}$ (QUESNEL, 1991, p. 13)
\end{abstract}

Acreditando que a loucura era resultado do domínio de uma única ideia sobre o espírito do indivíduo (QUESNEL, 1991), Maupassant cria um exército de monomaníacos que ganham voz, uma vez que, para poder classificar esses indivíduos como loucos, a razão tem de ouvi-los. Em um contexto no qual os loucos eram isolados em asilos e seu discurso silenciado, Maupassant não apenas Ihes dá voz, mas obriga a razão a ouvi-los.

Diferentemente dos discursos comuns, a fala do louco é ambígua, é contraditória, revela a impossibilidade do conhecimento seguro sobre o mundo. O louco percebe as inconsistências da realidade e dá lugar a esse discurso, discordando do "discurso correto", pois não encontra lugar para si nesse mundo. O louco evidencia o caráter fragmentário e problemático do mundo e a experiência de habitá-lo. Segundo Amarante e Torre (2011), não há melhor maneira de revelar os problemas desse mundo do que rompendo os nexos lógicos privilegiados pelo cotidiano em seu modo de operar.

$\mathrm{O}$ resgate do discurso do louco pela literatura propõe questionamentos e sugere novas organizações das regras de condução da sociedade. De acordo com Batalha (2003), ao recriar o mundo a seu redor, o louco gera uma nova verdade; esta obriga os outros indivíduos a relativizarem a lógica das práticas cotidianas.

A inserção da loucura na literatura fantástica vai retomar o tema da inadequação do sujeito, esse tema se liga diretamente ao indivíduo confuso do contexto histórico no qual nasce essa literatura. O louco, entende Batalha, ao recriar o mundo ao seu redor, gera uma nova verdade; esta obriga os outros indivíduos a relativizarem a lógica das práticas cotidianas. Para o fantástico, a personagem louca é muito privilegiada, pois coloca em cena uma lógica muito diferente da habitual. O delírio, a alucinação ou outras manifestações de desarranjo mental têm a vantagem de expor outra organização de

\footnotetext{
5 “'L'obsession de l'idée fixe' n'est visible ni sur le corps ni dans les gestes quotidiens du fou, il faut plutôt en chercher les signes parmi les mots balbutiants et maladroits qu'il prononce. Ainsi, avant de déclarer un personnage fou, les représentants de la raison n'ont d'autre choix que de se mettre à l'écoute de l'aliéné, à l'écoute du discours de la folie".
} 


\section{Revista do SELL \\ v. 5 , no. 2 \\ ISSN: $1983-3873$}

pensamento, mostrando não existir uma única lógica possível e questionando a ordem racional pré-estabelecida.

Retomando Foucault, em sua História da loucura na idade clássica (1972) o autor demonstra como o louco era percebido nas diferentes épocas. O panorama proporcionado por essa visão evidencia a relação estreita entre razão e loucura, sempre ligadas na história da humanidade, conforme já tivemos oportunidade de perceber; isso é decisivo na circunscrição da identidade do louco. Foucault chama a atenção para um fato muito anterior ao internamento dos alienados, a disseminação da lepra por causa das Cruzadas $^{6}$, o que levou à criação de inúmeros estabelecimentos para abrigar tantos doentes. Os leprosos, carregados de estigmas pela sociedade, eram mantidos apartados dela. O espaço destinado a abrigar os doentes foi mantido mesmo após o controle e a diminuição da população acometida pela lepra; mais tarde, foi utilizado para abrigar os doentes venéreos e, depois, os loucos. A internação do louco, feita por diferentes motivos nas diferentes épocas, mas sempre presente, o mantinha apartado da sociedade, pois esta não o reconhecia como igual e o estigmatizava, tanto quanto fazia com seus leprosos nos mais remotos tempos. Essa situação de marginalização pode ser percebida, em nosso corpus, conforme já vimos, e remete ao tratamento dispensado ao louco pela sociedade.

Foucault lembra ainda das naus de loucos da Renascença; segundo essa prática, os insanos eram colocados em barcos e deixados à deriva, à própria sorte, para atracarem em outra cidade ou morrerem no mar. Esses loucos não eram bem-vindos em suas cidades, por carregarem toda uma simbologia negativa, e quando atracavam em algum lugar, mesmo quando eram cuidados, não eram e jamais seriam os loucos daquela cidade. A imagem resgatada por Foucault liga-se diretamente ao gênero fantástico, entendido como o intervalo entre o estranho e o maravilhoso. O louco, por ser uma das personagens mais ambíguas da literatura (PONNAU, 1997), dialoga com a própria definição de fantástico, de gênero limítrofe entre dois outros, cuja característica maior é a manutenção da ambiguidade.

Se hoje é lugar comum admitir o indivíduo como um ser fragmentado e composto por várias identidades, na antiguidade não era assim. O homem não era independente, dono de seu destino; sua identidade era divinamente estabelecida desde seu nascimento, não estando, portanto, sujeita a transformações. Diversos momentos da história da

${ }^{6}$ Os soldados, que por diversos motivos precisavam ir até o Oriente, ponto principal de contaminação, traziam de lá a doença, espalhando-a por toda Europa. 


\section{Revista do SELL}

v. 5 , no. 2

ISSN: $1983-3873$

humanidade cooperaram para a mudança dessa concepção ${ }^{7}$, conforme aponta Stuart Hall, em seu A identidade cultural na pós-modernidade (2005).

As transformações associadas à modernidade libertaram 0 indivíduo de seus apoios estáveis nas tradições e nas estruturas. Antes, se acreditava que essas eram divinamente estabelecidas; não estavam sujeitas, portanto, a mudanças fundamentais. $O$ status, a classificação e a posição de uma pessoa na "grande cadeia do ser" - a ordem secular e divina das coisas - predominavam sobre qualquer sentimento de que a pessoa fosse um indivíduo soberano. O nascimento do "indivíduo soberano", entre o Humanismo Renascentista do século XVI e o lluminismo do século XVIII, representou uma ruptura importante com o passado (HALL, 2005, p. 25).

Em decorrência disso, às sociedades modernas, caracterizadas, de acordo com Anthony Giddens (1991), por suas constantes mudanças, pode-se associar o sujeito em crise. As transformações da sociedade causam impacto nas identidades pessoais, abalando as ideias que os indivíduos têm de si próprios, causando uma "perda de um sentido de si" (HALL, 2005, p. 9); isso gera o que chamamos deslocamento ou descentração. Esse deslocamento constitui uma crise de identidade para o indivíduo, pois este é tirado de seu lugar estável.

O sujeito, a partir de todos os descentramentos sofridos na modernidade, precisa conviver com a crise, situação explorada pela literatura fantástica. "O fantástico constitui uma forma de expressão específica da crise"8 (MALRIEU, 1992. p. 22), por isso não é espantoso que a literatura do século XIX encontre no fantástico uma maneira de resgatar e tratar as questões deixadas de lado pelo pensamento racionalista, procurando penetrar no mais profundo das percepções e dos sentimentos humanos. A estratégia de manter o leitor oscilando entre explicações possíveis tem a vantagem de sugerir possibilidades, sem dar qualquer resposta. Essa característica do fantástico reflete o espírito do homem do final do século XVIII e século XIX, produto do lluminismo, que carregava consigo os maiores avanços científicos ao lado das maiores dúvidas existenciais. Isso pode explicar

\footnotetext{
7 Podemos citar, como exemplos dos movimentos que mudaram a percepção do sujeito, a Reforma Protestante, pois colocou o homem diretamente ligado a Deus, sem a necessidade da intermediação da Igreja; o Humanismo Renascentista, pois trouxe o homem para o centro do universo; e o próprio lluminismo, pois conferiu ao homem um grande avanço científico, permitindo-lhe inquirir, investigar e decifrar grandes mistérios. Esses exemplos, lembrados por Hall, mostram o homem moderno reivindicando e assumindo seu lugar no mundo, deixando de lado a postura passiva diante do próprio destino, ainda que isso representasse abandonar os antigos alicerces e se embrenhar no desconhecido.

8 "Le fantastique constitue une forme d'expression spécifique de la crise".
} 


\section{Revista do SELL}

v. 5 , no. 2

ISSN: $1983-3873$

a razão pela qual a literatura fantástica tende a voltar-se cada vez mais para o próprio homem.

Nos contos do nosso corpus, importa frisar que o efeito fantástico é criado a partir de mecanismos que não remetem ao sobrenatural9; logo, a dúvida, a incerteza e a ambiguidade características do conto fantástico são construídas por meio do próprio cotidiano, percebido por mentes que não se ajustam aos padrões previamente estabelecidos. Dessa maneira sugere-se que o fantástico não está contido apenas em outro mundo em confronto com o nosso, mas no nosso próprio mundo. Desafiando o discurso vigente, o fantástico coloca-se como a forma estética dos debates intelectuais relativos ao sujeito com seus medos, incertezas e desejos.

\section{Referências}

AMARANTE, P.; TORRE, E. Michel Foucault e a "História da loucura": 50 anos transformando a história da psiquiatria. Cadernos brasileiros de saúde mental, v. 3, n. 6, 2011.

Disponível em:

http://incubadora.periodicos.ufsc.br/index.php/cbsm/article/view/1502/1725>. Acesso em: 20 fev. 2014

BATALHA, M. A importância de E. T. A. Hoffmann na cena romântica francesa. Alea, v. 5, n. 2. 2003. Disponível em: < http://www.scielo.br/pdf/alea/v5n2/a08v05n2.pdf>. Acesso em: 1 de ago. 2013.

BESSIÈRE. I. Le récit fantastique: la poétique de l'incertain. Paris: Librarie Larousse, 1974.

CARVALHO, A. A. S. (In)verosímil e fantástico ou a arte de provocar o medo. Carnets III, 2011.

FORESTIER, L. Notices, notes et variantes. In: MAUPASSANT, G. Contes et Nouvelles. Paris: Gallimard, 1974.

FOUCAULT, M. História da loucura na idade clássica. Tradução de José Teixeira Coelho Netto. São Paulo: Perspectiva, 1972.

FOUCAULT, M. O poder psiquiátrico: curso dado no Collège de France (1973-1974). Tradução de Eduardo Brandão. São Paulo: Martins Pontes, 2006.

\footnotetext{
9 Embora em algumas narrativas o elemento sobrenatural seja insinuado, situação comum no fantástico tradicional, é a loucura, o olhar enviesado do louco sobre o mundo que o cerca que oferece a maior contribuição para o efeito fantástico do nosso corpus.
} 


\section{Revista do SELL}

v. 5 , no. 2

ISSN: $1983-3873$

GIDDENS, A. As consequências da modernidade. Tradução de Raul Fiker. São Paulo: Editora UNESP, 1991.

HALL, S. A identidade cultural na pós-modernidade. 10. ed. Rio de janeiro: DP\&A; 2005. MAUPASSANT, G. Fou ? In: . Contes et Nouvelles. Tome I. Paris: Gallimard, 1974.

La folle. In: Contes et Nouvelles. Tome I. Paris: Gallimard, 1974. . L'auberge. In: . Contes et nouvelles. Tome II. Paris: Gallimard, 1979.

- Le docteur Héraclius Gloss. In: . Contes et Nouvelles. Tome I. Paris: Gallimard, 1974.

. La chevelure. In: . Contes fantastiques. Editions Marabout, 2005. . La reine Hortense. In: Contes et Nouvelles. Tome I. Paris: Gallimard, 1974. . Le Horla. In: Contes et nouvelles. Tome II. Paris: Gallimard, 1979. . Lettre d'un fou. In: . Contes et nouvelles. Tome II. Paris: Gallimard, 1979. . Lui ? In: . Contes et Nouvelles. Tome I. Paris: Gallimard, 1974.

. Mademoiselle Cocotte. In: - Contes et Nouvelles. Tome I. Paris:

Gallimard, 1974.

. Qui sait ? In: . Contes et nouvelles. Tome II. Paris: Gallimard, 1979. . Un fou ? In: . Contes et nouvelles. Tome II. Paris: Gallimard, 1979.

MALRIEU, J. Le fantastique. Paris: Éditions Hachette, 1992.

PONNAU, G. La folie dans la littérature fantastique. Paris: Presses Universitaires de France, 1997.

QUESNEL, C. Folie et raison chez Guy de Maupassant. 1991. 92 p. Dissertação (Mestrado em Artes) - Departamento de língua e literatura francesas, Universidade McGill, Montreal, 1991. Disponível em: <http://digitool.library.mcgill.ca/R/-?func=dbinjump-full\&current_base=GEN01\&object_id=60556>. Acesso em: 15 jan. 2015.

ROAS, D. (Org.). Teorías de lo fantástico. Madri: Arco/Libros, 2001.

TODOROV, T. Introduction à la littérature fantastique. Paris: Seuil, 1970.

VAX, L. L'art et la littérature fantastiques. Paris: Presses Universitaires de France, 1974. 